This is the version of the article accepted for publication in Compare: A Journal of Comparative and International Education published by Routledge Taylor \& Francis Group. Accepted version was published online on 06 February 2019, https://doi.org/10.1080/03057925.2018.1559036

\title{
Interrogating quality: minority language, education and imageries of competence in Nepal
}

\begin{abstract}
Quality education is increasingly considered essential for human development. However, the mainstream approach to quality as a neutral technology often ignores deeply embedded issues of power relations. This article interrogates the taken-for-granted idea of 'quality education' by exploring the ways in which students navigate the assumption of quality education in two mother-tongue schools in Nepal. Drawing on the concept of language ideology, this article shows that the perceived social prestige associated with a language choice is closely intertwined with the discourse of quality education in Nepal. In this context, the students secure 'imageries of competence' by repeatedly drawing attention to more acceptable indicators of 'quality' such as high examination scores, English proficiency and continuation of higher studies. This article foregrounds the power relations embedded in the perception of quality education and intends to be of wider analytical relevance to other socially heterogeneous contexts beyond Nepal.
\end{abstract}

KEYWORDS

Minority language; language ideology; quality education; Nepal; South Asia

\section{Introduction}

Quality education is increasingly considered an important way to achieve human development and to improve the life chances of children, especially those belonging to marginalised groups (UNESCO 2015; Tikly and Barrett 2011). This 'quality turn' in education has led to two distinct approaches in relation to minority-language education.1 On the one hand, some education programmes and policies encourage the use of mother tongue as the language of education in order to facilitate student learning (Ames 2012; Cummins 1979). These studies confirm that children are likely to understand better if they are taught in their first language. The use of mother tongue in schools has also been proven to have a positive impact on school attendance and retention (UNESCO 2011). On the other hand, a few education programmes refrain from the use of mother tongue in education because of the perceived decline in the utility of minority languages (Fraser-Gupta 1997); its use is considered a hindrance to more 
'useful' education provided in the dominant language (Goody 1975). This contradictory perception of the impact of minority language in quality education has often led to ambivalences in its incorporation in mainstream education policy and practice (Burnett 2012).

This ambivalence over the use of minority language in education reveals an 'intensely valueladen' idea of education (Street 1984, 2011). The contradictory idea that mother-tongue education, despite the evidence for its enhancing student learning, is perceived as low-quality education reveals the ways in which various languages are differentially valued in a given context. Scholars have used the notion of 'language ideology' to explain this power relation embedded in the evaluation of language (Silverstein 1979; Woolard and Schieffelin 1994). The construction of hierarchies between languages, as shown in the seminal work of Bourdieu (1984), are relations of symbolic power between different social groups. Bourdieu argues that such power is translated into 'distinctions' through institutions such as schools. In the context where minority languages are used for the purposes of education, the symbolic capital acquired through such an education is often called into question. In this article, I will explore these tensions in minority-language education by drawing attention to the ways in which the students in minority-language education negotiate the social value of different languages.

This article is based on fieldwork I conducted between August 2013 and March 2014 in Nepal. The fieldwork focused on two schools, one in Kathmandu district (Newa School) and the other in Kapilabastu district (Buddhabhumi School). I chose to study these two schools for two reasons. First, they were both well known for using children's 'mother tongue' as the medium of instruction for at least three years. Second, both the schools were well attended by students. At the time of fieldwork, there were a total of 275 students in Newa School and 1048 students in Buddhabhumi. Newa School was established in 1990 as a private school and used the local 
language, Nepal Bhasa2, as the official medium of instruction from nursery to Class 10 Buddhabhumi was established in 1987 as a government secondary school. Since 2010, the school started using Dangaura Tharu3 as the medium of instruction at the primary level. During my fieldwork, I sought to explore the ways in which quality education was understood in these schools. For this purpose, I conducted informal interviews with students, parents and teachers, observed classroom teaching and staff meetings, and participated in the everyday life of the schools.

Drawing on the concept of language ideology, this article shows that the social prestige of language choice is closely intertwined with the discourse of quality education in Nepal. In the following sections, I will highlight the ways in which 'language ideology' foreshadowed the perception of quality in education. I will also discuss how students constructed the imageries of competence by repurposing the perceived indicators of 'quality' such as high scores in national-level exams, proficiency in English and continuation of higher education in good colleges. By foregrounding the power-laden process through which the social value of 'quality' is produced, I direct attention to the complex relationship between the discourse of quality and minority-language education.

\section{Quality discourse, language ideology and imageries of competence}

Quality education, the UN Sustainable Development Goal (4)4 affirms, is the foundation for improving people's lives. The importance of quality in education is increasingly articulated as a crucial link to human development (UNESCO 2015; Drèze and Sen 1995). Universal education is thus expected to provide 'Education for All' so that all individuals are positioned well in society. Individuals, through education, are believed to gain 'symbolic capital' in the form of knowledge, skills and language that equip them to cope with the demands of an 
increasingly changing world (Levinson, Foley, and Holland 1996). Access to quality education is considered crucial in order to improve life chances and social mobility, especially for children of socially marginalised groups (UNESCO 2015; Tikly and Barrett 2011). This process of claiming individual mobility and social status, as Urciuoli (1993) points out, represents the 'triumph of individual virtue'. In this respect, education is considered as a 'great leveller' of social differences, through which the disadvantaged may gain access to the dominant social capital. Within the discourse of 'quality education', it has been well established that children's access to and performance in mainstream education is significantly improved if they are taught in their mother tongue.

According to UNESCO (1951, 691): 'Pupils should begin their schooling through the medium of the mother tongue because they understand it best and it will make the distance between home and school as small as possible.' Studies in different parts of the world have substantiated that learning through one's mother tongue improves the wellbeing of students and positively influences school results (Ames 2012). Similarly, Cummins (1979) has advanced the theory of 'language interdependence' and explained that children should have 'basic interpersonal communicative skills' (BICS) in their native language. If the students are taught in a language they already know, they will understand more of what they are taught and develop Cognitive and Academic Language Proficiency (CALP). He argues that this 'step incremental learning' process, moving from the known to the unknown, not only enhances the academic performance of the students, but also makes the education system more child-friendly (UNESCO 2015). In addition, mother-tongue education is also considered to address social injustices embedded in wider society and to contribute towards ensuring inclusive education (Tikly and Barrett 2011). 
In Nepal, such a perspective has guided the Ministry of Education and international organisations such as UNESCO and the UnitedMission to Nepal (UMN) to develop MultiLingual Education (MLE) programmes. According to the 2001 census, 52\% of Nepali people do not speak Nepali as their first language. In 2011, this figure increased to 55\%. Even though census data are highly controversial, these statistics indicate the partial reach of Nepali language across the population. Many researchers have, therefore, asserted that the use of aNepali-only policy in education institutions systemically disadvantages the non- Nepali speaking population (Phyak 2011; Awasthi 2004; Giri 2009, 2011; Yadav 1992). Recognising this 'language disadvantage', the Government of Nepal and institutions like UNESCO now advocate that if education is imparted in the language spoken by the child at home, it will ensure better outcomes and also tackle issues of low admissions, high rates of school absenteeism and high dropout rates (UNESCO 2011; MoE 2003; Limbu 2006).5

Officially, this space for the use of mother tongue in education opened up after the 1990 Constitution of Nepal declared Nepal as a multi-ethnic (bahu jatiya) and multilingual (bahu bhasik) country, a concept further reiterated in the newly crafted Constitution of 2015 . The 2015 constitution also declared the right to primary education in one's mother tongue as a fundamental right. Such a declaration marked a radical departure from a historical context where the use of languages other than Nepali was considered to violate the law (Whelpton 1997). The idea and practice of mother-tongue education was thus played out largely in changing discourses of social inclusion, multi- ethnicity and social justice increasingly espoused not just by language enthusiasts, but by the Nepalese state itself. However, despite these constitutional provisions, mother-tongue education continued to be one of the most contentious political issues in Nepal (Noonan 2006). Some scholars identify mother-tongue education as hindering the prospect of a unified national community (Sharma 1992; Bandhu 
1989). By contrast, ethnic activists and policy-makers favour mother-tongue education from the standpoint of social justice, human rights and access to education, and as a challenge to the hitherto homogenizing tendency of the Nepali state (Bhattachan 1995; Phyak 2011; Awasthi 2004; Giri 2009, 2011).

Nonetheless, the Government of Nepal offered Multi-Lingual Education (MLE) as a technical solution to address the deep-rooted tensions around issues of ethnicity in Nepal (UNESCO 2011). MLE was further taken up by the School Sector Reform Plan 2009-2015: 7500 schools were targeted to introduce education using mother tongue for children from grades one to three. In line with this, the Government of Nepal launched a pilot project onMLE in seven primary schools in 2009. Under this project, education is to be imparted in the mother tongue. Inside a classroom this means that students learn school subjects like maths, science and social studies in their first language (usually mother tongue - L1), then are introduced to second (Nepali L2) and third (English - L3) languages as 'subjects', and gradually transition to L2 and L3 as mediums of instruction. Despite these 'process and learner-centred' discourses around quality education (Tikly and Barrett 2007), the relationship between language and education continues to remain complicated. In the historical context of Nepal, where school education did not include any languages other than Nepali and English, this institutional change demanded a significant attitudinal shift. Studies on education in Nepal (Valentin 2011; Burnett 2012; Karki 2016) have shown that the medium of instruction shapes the imageries of competence acquired through those schools. In her ethnographic study of the squatter settlements of Kathmandu, Valentin (2011) notes that claiming schooled identity was often about gaining a particular kind of formal education, often associated with mastery over dominant language/s. 
Drawing on a comparative study of three schools in Nepal, Burnett (2012) calls thisNepal's educational dilemma, where the choice of language in schools pose dilemmas about ideas of 'success'. The perception of Nepali and English as the 'language of the educated', as I have argued elsewhere (Pradhan 2017), continue to influence the assumption that English-medium boarding schools are 'quality' education institutions (Karki 2016). Such a perception has resulted in the rapid expansion of private schools in Nepal (Bhatta and Budakothi 2013). These imageries of competence indicate apparently 'common sense notions' that position different languages in a hierarchy (Rumsey 1990, 346; Noonan 1996). In these contexts, 'quality' in education is often used as a shorthand for mastery in the dominant language/s. Scholars have therefore been critical of such a conception of education as a linear pathway to development because it envisages education in universal and ahistorical terms. Authors such as Street (1984) have vehemently argued that this view of education as a 'neutral' technology assumes its existence independent of the cultural context and meanings. He demonstrates that educational models are inextricably linked to cultural and power structures of a society and have effects in creating 'inequality for those who lack it and advantages for those who have it' (Street 1984, 2). Education is understood to impart a 'hidden curriculum': particular socially constructed technologies are used within given institutional frameworks for specific social purposes (Bowles and Gintis 1976). Similarly, Bourdieu and Passeron (1979) have drawn our attention to the way in which education plays a particularly important role in legitimating and reproducing symbolic capital. Students whose social backgrounds do not have a close connection with the dominant symbolic capital are thus at a decided disadvantage in mainstream education.

Increasingly, the concept of 'language ideology' (Silverstein 1979; Woolard and Schieffelin 1994; Kroskrity 2004) has been used to explain these mediating links between overarching 
social structures and forms of everyday language exchange. As Bourdieu (1984) has argued, such judgements about quality are related to social positions of the speaker and are themselves acts of social positioning, ways for an educated person to claim 'distinction'. Such a distinctive identity serves to assure people that one possesses the valued symbolic capital, including the particular kind of knowledge and language competence that is required to position oneself well in a social hierarchy. Language ideology, Silverstein (1979) argues, are 'sets of beliefs about language articulated by users as a justification of perceived language structure and use'. Following similar analysis, other scholars have also located linguistic practices as part of a larger system of inequality (Gal and Irvine 1995; Irvine 1989). This paper uses the lens of 'language ideology' as an analytical vantage point to understand not only the way language is used in education, but also the social relations mediated by the language.

\section{Navigating language ideology}

In this section, drawing on the concept of 'language ideology', I will discuss the ways in which the percieved social prestige of language can mediate the social relations of the speaker. Ochs (1992) notes that linguistic structures become associated with social categories not directly, but indirectly through a chain of semiotic associations. In these contexts, the linguistic behaviour is unjustifiably seen as deriving from speakers' social, intellectual or moral character (Gal and Irvine 1995; Irvine 1989). In educational contexts, these language ideologies can unfold an identity-making process that distinguishes students as members of particular groups with quite specific characteristics (Paris 2011; Carney and Madsen 2009; Cummins and Early 2011). It is this social meaning of language, rather than its being a simple communicative code, that posed a challenge in both the schools, as I will illustrate using 'ethnographic portraits' (Jeffrey and Dyson 2008) of two students: Janak Shrestha, a student in Newa School; and Santosh Tharu, a student in Budhhabhumi. All the names used are pseudonyms. 


\section{Smart students - dull students}

In Newa School, teachers often talked of Janak Shrestha6 as one of their exemplary students. Janak was part of the first cohort of students who appeared in a School Leaving Certificate (SLC) exam from Newa School in 2010 and passed with distinction. As a flagship programme of Newar ethnic activism, Newa School was founded with the objective of teaching Nepal Bhasa to the younger generation and ensuring its revitalisation. However, since the school was operating with the national education system, Newa School could use Nepal Bhasa for education only as long as what they taught adhered to the government stipulated curriculum guidelines and other subjects such as Nepali, English, Science, Maths and Social Studies. In addition, the students in Class 9 could opt for either Nepal Bhasa or Optional Mathematics (Trigonometry). Janak Shrestha was one of the six students of Newa School who achieved a distinction in SLC. He went on to study a short course in India. At the time of fieldwork, in 2014, he was studying Chartered Accountancy. He had also been teaching optional maths in Newa School for the past two years, as a part-time teacher. Throughout the 10 years of his schooling in Newa School, he studied Nepal Bhasa as a subject. When I asked him if he took Nepal Bhasa in SLC, he said:

I studied here since nursery. So, I took Nepal Bhasa from then till Class X. In the final year of my schooling, I chose Trigonometry as an optional subject in SLC. I took Nepal Bhasa classes, but did not give Nepal Bhasa exam in SLC.

Indeed, a major challenge for minority-language schools such as Newa School has been to motivate their students to opt for Nepal Bhasa at the SLC level. Other studies on minority languages in Nepal have shown that minority languages are being circumscribed by the low status conferred on them: younger generations no longer prefer to use their mother tongues (Pettigrew 2000; Turin 2013). Like Janak Thapa, many students in Newa School, when asked 
to choose between Nepal Bhasa and Trigonometry, opt for the latter as an optional subject in Class 9 Based on what they choose in Class 9, they write their School Leaving Certificate Exam at the end of Class 10 Many students prefer not to choose Nepal Bhasa because it is considered an 'easy subject'. Maths and science are agreed to be the difficult subjects and therefore confer higher prestige. Kavita Shrestha, Nepal Bhasa teacher in Class 9 and 10, often lamented: 'Top students always take optional maths. We do not get quality students in Nepal Bhasa.' Most students chose Optional Maths in the first instance and only when they fail, opt for Nepal Bhasa. Since Optional Maths requires skills in solving complex mathematical questions, the students who chose Optional Maths are considered by their peers as the 'one[s] who can study' (padhna sakne), i.e. the smart ones. The students who choose mother tongue were written off as 'one who cannot study' (padhna nasakne), i.e. the dull students.

This binary between smart students and dull students was based on the subject they chose for their final exams, not their knowledge of the chosen subject. These 'identity making' activities in the school were thus unsolicited acts that labelled students based on their choice of 'easy' subjects and 'difficult' subjects. This idea was invariably linked with the 'language ideology' that judges speakers based on their language (Silverstein 1979). In her ethnographic study of women's adult literacy programmes in the US, Luttrell (1996) argues that such a process of self-making is inherent in the pursuit of 'becoming somebody'. She illustrates the ways in which these aspirations of 'becoming somebody' are linked with individuals' gender, race and class positions. In this process, individuals choose from the options offered by society in very unpredictable ways. In Newa School, students such as Janak Shrestha chose to position themselves as smart students by choosing 'difficult' subjects, even though the school was well known for its education in Nepal Bhasa. Moreover, this perception pushed several students to choose Optional Maths even when they were not strong in maths. 
One day, the Nepal Bhasa teacher told me about Saurav Khadgi, a student in Class 9 who had opted for Optional Maths. 'Look at Saurav. He fails in Maths every year. Since the time he was in Class 5, he has had to repeat maths exam several times. And yet, he chose Optional Maths.' Several teachers in Newa School tried to talk Saurav out of it. However, he insisted that he needed to find out for himself whether he could do Optional Maths or not. In the first-term examination in Class 9, he failed this paper; no one in the school was surprised. Kavita Shrestha tried to get him to opt for Nepal Bhasa before it was too late. Nevertheless, Saurav continued in Optional Maths. Consequently, fewer students attended Nepal Bhasa lessons in Class 9 and 10. During my fieldwork, in 2013-2014, only seven students had opted for Nepal Bhasa, as a subject, from a cohort of 25 in Class 9.

Many teachers saw the choice between mother tongue and subject such as mathematics and science as an unfair choice, and especially the new proposal that the government introduce Computer Science as an optional subject. Many felt that if Nepal Bhasa was pit against a much sought-after subject such as computer science, no student would opt for it. They much rather preferred students to be offered two baskets of options so they could compare like with like. One basket, in their view, should offer students choices between languages while the other should allow them to choose between technical subjects. They objected to students having to choose between a language and a technical subject. To be sure, this problem of Nepal Bhasa was therefore paradoxical for Newa School. The school was indeed proud that students were able to do other subjects and therefore was able to set an example that the use of mother tongue does not hinder their students' education. But at the same time, this apparent success was inhibiting students from choosing Nepal Bhasa, because imbibing the identity of a 'smart student' meant choosing optional maths. 


\section{Not becoming fools}

There was a similar process of identity-making in Budhhabhumi School, where Santosh Tharu studies in Class 5. Santosh lives in the same village where the school is located, with his parents and younger brother and sister. He is very proficient in Tharu and speaks good Nepali. Telling me about his life, he shared:

I speak Tharu with my friends and family. I teach my sister and brother in Tharu when they cannot do their homework. It is easier to understand the lesson when I explain in our language. I was in Budhhabhumi before MLE started. When I was in primary school, my teachers used both Tharu and Nepali. They explained lessons in Tharu but the books were in Nepali. I teach my younger brother and sister Nepali too. It is important to learn Nepali otherwise people will 'make a fool out of us' (buddhu banauchha: in Nepali). We need to learn Nepali so that we are not made fools out of.

Buddhabumi is situated in the middle of a Tharu community. The school had recently started using Tharu as the official language of instruction in primary education. The MLE programme was initiated in collaboration the Ministry of Education and United Mission to Nepal (UMN). Buddhabhumi was well known for its MLE programme; the school received a regular stream of visitors who came to the school to understand the ways in which they had been implementing the programme. However, in Santosh's conception, the idea of 'not becoming fools' was dependent not on what he learnt in school, but his perceived competence in Nepali/English. This assumed link, between the imageries of competence and the knowledge of language, was associated with the idea of Nepali/English as 'the language of the educated'. Several authors have documented that historically Tharus have suffered due to the unfamiliarity with the Nepali language and the organs of the state. McDonaugh (1997) notes that 'the progressive extension of the apparatus of the Nepalese state was accompanied by a steady erosion of local Tharu influence'. Guneratne (1998) also observes that soon after Malaria was eradicated, land in Terai became a valuable asset and new legislation on land tenure and revenue was brought into 
action. For the indigenous Tharus, this meant that much of the land formerly controlled by Tharus passed into the hands of immigrants mostly Brahmins, Chetris, and Thakuris from the hills. Many of these immigrants used their education, and their caste and kinship affiliations with local government functionaries to, appropriate Tharu land. In addition, thousands of Tharu peasants fell into debt and became bonded labour for their new landlords. (Guneratne 1998, 754)

One of the main concerns of the students was to ensure that they had control over these languages to become the knowledgeable person that school education promises - to secure the identity of an 'educated person' (Levinson, Foley, and Holland 1996). Santosh's concern and this story also indicate the pervasive mistrust against the pahadi mul (the term commonly used to refer to Nepali people belonging to a hill community). This also indicates deep-rooted intergroup tension that exists in Nepal's Terai region, expressed through linguistic terms. In addition, though Tharu is the language of everyday communication and is now the official medium of instruction in the school, Nepali and English are still the dominant languages of the society. This internal relation of power between different languages played an important role in establishing the legitimacy of the language in the everyday lives of the students. As Pigg (1992) has very incisively presented, an ideology of modernisation alters the formulation of local identities with an implicit scale of social progress: from rural locality to urban modernity (represented by educated and elite city dweller) and from ethnic identities to national identity (represented by high-caste hill identity), thus creating categories of social differentiation.

\section{The label of 'low-quality education'}

Moreover, these imageries of competence functioned not only to gauge the ability of the students but also of the schools, as Janak Shrestha further elaborated: 
When I scored distinction, my friends from other school were surprised. My friends used to make fun of my school because it teaches in the mother tongue. They thought I might not be able to do well in SLC because I study in Newa School. When I got a distinction in SLC, they finally shut up.

Janak Shrestha and his friends' perception that Newa School students would not do well in exams indicates the language ideology that inherently links mother tongue with 'low quality' education. This judgement on the quality of school education was not based on the actual examination results of the school, since Janak's cohort was the first group of students to appear in the SLC exam. This perception of a naturalised link between language and its social value indicated a judgement based on the existing social hierarchy. Even while this association may not be accurate, it had a real impact on students' self-evaluations. Janak further elaborated:

But even after getting a distinction in SLC, I was a bit worried in the beginning. After my SLC, I went to Prime College. There were students from schools such as White House . . big schools. I had to compete with them in the same class. But I topped the class. Despite coming from this school, I got 84\%. I was the top student in the entire college. After that incident I realised no matter which school you come from, it really depends on you. When I stepped out of this school, I definitely had doubts. Now that I have met students from other schools, I don't feel that anymore.

Given the low status rendered to languages other than Nepali, the use of the mother tongue in school was perceived as possibly hindering the overall quality of education. Students in these schools often expressed the pressure to work harder and perform better. I witnessed a similar incident in Newa School when a group of students were leaving for an inter-school quiz competition. These students were competing with students from other private schools. Though Newa School is a private school, it did not enjoy the same status as other English medium boarding schools.7 The students said as they were leaving: 'We have to try to win this competition. If we lose, they will say it is because we go to Nepal Bhasa school. Those who do not know us, expect us to do badly.'Many students in Newa School felt this pressure to 
prove themselves and the quality of their education continually. Some students responded by not participating in inter-school competitions. As the headteacher of Newa School said: 'In the initial days of the school, we were warned of going against the grain by delivering education against "national unity" and "playing with" students' futures (bhabishya barbad yayegu: in Nepal Bhasa).' It was therefore important, both for the school and students, to prove that they could achieve overall quality in education through the use of languages other than Nepali. The school's overall performance played an important role in gaining acceptance as a good school. She continued: 'It was after $100 \%$ of our first cohort performed well in SLC and when some students got distinctions, that our school started to be seen as giving good education (padhai ba la gu: in Nepal Bhasa).'

Students from lower socio-economic backgrounds attended both the schools, attracted as they were by their lower tuition fees and ease of access. Other families chose to send their children to English-medium private schools that charged much higher tuition fees based on their reputation as quality education institutions. Parents who sent their children to private 'Englishmedium boarding' schools always mentioned that they perceived private school as 'better schools'. One of the parents proudly told me: 'Boarding school students are smarter than the government school students.' This implicit judgement on quality in education, based on the language of instruction and type of school, positioned the schools in a speculative scale of hierarchy, with English-medium schools at the top, followed by Nepali-medium schools and mother-tongue schools respectively.

\section{Constructing imageries of competence}

In order to navigate the social value attached to different languages, students sought to construct imageries of competence through more acceptable measures such as national- level 
examination, English language proficiency and higher education. These external measures of 'quality education' not only facilitated the day-to-day functioning of the school but also mitigated doubts, if any, on the relevance of mother-tongue education. The idea that mothertongue education is geared towards uniform national education goals also provided an acceptable framework in the context of general underachievement in education. In the following section, I will discuss these further.

\section{Performing well in exams}

When I had entered the Newa School building for the first time, I had noticed a board with photos of 23 students who passed the School Leaving Certificate (SLC) examination in 2010.8 Under each photo was the name of the student and the percentage they obtained in the SLC examination. The board displayed that two students achieved 'distinction', 20 passed with 'first division' and two with 'second division'. This board was strategically placed above the accounts section window, where parents often visited to pay school fees. In the head teacher's office too, there were certificates of appreciation for achieving 100\% pass rates in SLC.

The School Leaving Certificate exam is a national-level secondary school examination administered by The Controller of Examinations Division of the Ministry of Education. It is conducted annually for Class 10 students and marks the completion of school education. It is also mandatory for all the students in the country who wish to continue their higher education. Though the value of this exam is highly controversial, it nonetheless acts as a gateway for higher education, is an important credential for entering the labour market (Thapa 2013; Valentin 2011) and is often referred as an 'iron gate' that students must pass through in order to have a bright future. At the national level, the pass rate for this exam is quite dismal. In 2014, only $43.92 \%$ of students, of a total number of 548,248 students, passed the exam (The 
Himalayan 2014). In 2013 and 2012, the pass rates were $41.57 \%$ and $46.16 \%$ respectively. A very small proportion of students achieved high grades. In 2014, only $3.3 \%$ got distinction $(80 \%)$, and only $15.2 \%$ of the total number of students taking the exam achieved the first division (60\%). This academic achievement of the school was well accepted by the parents. The parents confirmed that one of the reasons they sent their children to this school was because the 'education is good' here despite using Nepal Bhasa, and, furthermore, it was affordable or free compared to other private schools in the neighbourhood. In this general context of underachievement in education at the national level, the educational outcomes gained by both these schools were remarkable. Newa School has been getting $100 \%$ pass rates in SLC since its establishment, with many students getting distinctions. Throughout my fieldwork period, I often heard teachers, students and parents say that, in their experience, 'the use of mother tongue has not hindered quality education in this school.'

This narrative of exam results was repeatedly presented in front of the visitors to overcome the common conception that mother-tongue education could potentially act as an obstacle to quality education, especially in the context where Nepal Bhasa was not the language of everyday communication for all the students. As Sunita Shrestha, one of the past students at Newa School told me:

Many people told me that education would not be good in this school. But because of our excellent performance in SLC, they got to know that education in this school is not bad. Our result was not bad at all ... we had many distinctions.

In Budhhabhumi, the board listing the educational outcome of the school was displayed in the head teacher's room. The board showed that Budhhabhumi had achieved 60-100\% SLC pass rates in the last few years. Both schools displayed a board with the annual SLC examination results. These displays served two purposes: firstly as a 'social audit' mechanism of good governance in school policy, where each school is required to display their results publicly and 
be accountable for it; and secondly, they were also a testimony to ‘quality education' provided by the school. Yadava (2007) cites school-level educational statistics compiled in Nepal in 2005 and shows that the dropout rate for ethnic minority children in Grade 1 is 50\%, which places them significantly more at risk of academic underachievement than is reflected in Nepal's overall national literacy rates. Especially given this low educational achievement of the ethnic population in Nepal, achieving high educational outcomes was one of the key goals of the schools. This repeated emphasis on their performance in the national-level examination also reflected the schools' attempt to be part of the national education system.

\section{'I learn English too'}

One day I asked Janak Shrestha what his friends thought of him attending a Nepal Bhasa school. He explained that his friends often asked why did he not attend a boarding school. When they asked that, Janak mentioned: 'I often I tell them - I learn English too.' Many students in Newa School shared similar experiences. During these conversations with friends, neither Janak nor other students of Newa School had to prove their actual competence in English. The very fact of being identified as a minority-language school positioned the school lower in the educational hierarchy. Similar experience was shared by Santosh Tharu. 'If you do not know Nepali and some English, you will be gawar (an uneducated rural person: in Nepali),' he told me in one of our conversations. Pointing to our conversation in Nepali, he mentioned: 'If I have to speak to people like you properly, I have to use Nepali.' He added: 'When I speak Nepali, the Tharu in me comes out.' My conversation with Santosh was in Nepali and he was fluent in it. I asked him to explain what he meant by it. He said: 'When we speak Nepali in our village, it is not like the Nepali that you speak. We say Garho bhai halchha instead of Garho hunchha ['(It) is difficult': in Tharu inflected Nepali]'. Santosh's eagerness in mastering 'unmarked' Nepali and learning English reflects the language hierarchy in 
contemporary Nepal. As I sat down in the open space in front of his thatched house, his father asked me to put some sense in 'Santosh's head'. He asked me to convince Santosh to concentrate on his studies more than he does, so that he could eventually go to Kathmandu for his further studies. As the eldest son of the family, Santosh's father wanted him to take more responsibility and financially support the family.

Santosh and his father's idea of education as a way out of economic hardship reflects the mainstream discourses that shape narratives around education. Both Newa School and Budhhabhumi, therefore, taught Nepali and English as a compulsory subject, English conversation lessons and Budhhabhumi offered additional English classes to their students from Grade 4 onwards. In the context where English-medium education is considered important, the fact that these schools also taught in English was seen an assurance of good education. This also helped the students to simultaneously use different languages in school, home and other social settings. Describing similar contexts in Nepal, authors such as Hangen (2010) and Sonntag (1995) have pointed out that ethnic movements in Nepal do not necessarily position themselves in opposition to English. English language is utilised as a neutral language and often serves to elevate the status of the mother-tongue speakers.

Santosh's eagerness in mastering Nepali and learning English reflects the language hierarchy in contemporary Nepal. As a first-generation multilingual member of his family, he perceives language as an opportunity for better prospects for his family. In his idea of progress, the movement in language, for example, from Tharu to English, is as important as the movement in space, for example, from his village to city. He interpreted that he would be restricting his social and spatial mobility if he limited himself to the Tharu language. The preference for language, in Santosh and Janak's case, was not only about acquiring linguistic skills for 
communication and social exchange. At the local level, both Nepal Bhasa and Tharu had a lot of currency in local communication. The emphasis on learning the dominant language was also about 'fitting in' the larger social context shaped by differening values attached to different languages. As Pettigrew (2000) points out in her analysis of language use in the Gurung community, many Gurung parents are 'very aware' that they do not speak fluent Nepali. They, therefore, want their children to acquire 'the fluency that they lack'. This was not only about the language competence required for education and/or employment, but also about the communication of social background that it portrays.

I did not get into an in-depth inquiry into English language teaching in these schools. However, it was clear in most of my class observation that there was room for improvement. The wall painting in Class 2 in Budhhabhumi had incorrect spellings of the days of the week and some months, for example: 'Thusday', 'Teusday', 'Auguest' and 'Novmber'. Children were rotelearning these spelling. Some children pointed out the mistake and learnt the correct spelling from the book. However, the fact that it was written on the school wall made it more accessible for most students and they continued to use the incorrect spelling. Authors like Phyak (2011) and Giri (2011) have cautioned against this haphazard use of English in schooling. They argue that effective learning and teaching of English needs to be done 'at the right time, by the right people and for the right purpose' (Phyak 2011, 13). Nonetheless, as Caddell (2006, 213) notes, the 'use of English, even of a very poor level, is considered to connect students to a wider international project, offering a greater potential for mobility'.

\section{Higher education}

As more students graduated from the schools, their life trajectories became a significant reference point to measure the quality of education. Similar to the stories of Sunita Shrestha 
and Janak Shrestha of Newa School, the students' admission into well-reputed colleges and in sought-after courses like Biology and Chartered Accountancy was considered an important measure of the perceived success of the school. Though Janak Shrestha's friends in the college, as well as he himself, doubted his own educational abilities, given his background in mothertongue school, he was able to prove himself through good results and his further education. Many students of Newa School had gone on to study subjects like Nursing, Lab Technician and Science; some of them were studying Management and Commerce.

At the time of my fieldwork, there were at least six ex-students teaching various subjects, including Nepal Bhasa, in Newa School. In Budhhabhumi, many students studied Education and Management at the nearby College. Some students also went to Kathmandu for higher education. Some had done their higher education in linguistics, specialising in Tharu language. The range of higher education and career options demonstrated by previous students of the school was seen as an apparent success of the school in giving an excellent education. Higher education thus played an important role in shaping students' aspirations. Santosh Tharu, the student from Budhhabhumi, shared an aspiration for higher education just like most of his peers. As he explained: 'There is a College nearby. But I want to go to Butwal or Kathmandu for higher education. I want to get a good education. I want to study Management.' As observed in other studies of formal education in Nepal, schooling was seen as a means to reach higher education goals and associated with the future opportunities it promises. As an increasing number of students was able to make the transition to higher education, the mother-tongue education offered by the schools became more acceptable.

Higher education also served as a testimony to the 'success' of the schools. This was well taken by parents and students. Many parents chose these schools because they had had 
relatives who had scored very high marks in exams at the schools and were now studying in good courses. According to a mother of a student at Newa School, she sent her children here on her sister-in-law's recommendation.

My sister-in-law sends her two children to this school. They are both doing very well. One of her daughters is now studying Nursing. Education is good here. Some people say that this is Newa Bhay School and education is not very good. No. Not in my experience. I think all the schools in this locality are similar. Earlier, I sent my children to some other school, but their level was still the same. The education there was not much different than what they get here. Here they learn Nepal Bhasa, but the books for other subjects are the same.

Though not all the students from the schools chose higher education after the completion of school, the range of higher education trajectories of most of the students provided a sufficient basis to shape the local perception of these schools as good schools.

\section{Conclusion}

This article points out the need to pay attention to the 'perception of quality' as an important way to understand the language hierarchy embedded in minority-language education. In both the schools studied, the idea of 'quality' was primarily shaped by the social value attached to different languages. Such assumptions resulted in the speculative evaluation of mother-tongue education as providing low-quality education. In these contexts, 'quality' was often used as a shorthand for proficiency in dominant languages such as English. Drawing on the concept of 'language ideology', this article demonstrates that the evaluation of quality was not necessarily based on actual educational outcomes, but an imagined perception of the intellectual capability of the speaker based on their language competence. Such an implicit judgement on quality in education, based on an apparently naturalised link between language and its social value, positioned the schools in a speculative scale of hierarchy as well: English-medium schools at the top, followed by Nepali-medium schools and mother-tongue schools respectively. 
Given this power-laden process through which social value of 'quality' is produced, the students in Newa School and Buddhabhumi sought to secure imageries of competence by repeatedly drawing attention to more acceptable indicators of 'quality' such as high scores in national examination, English language proficiency and continuation of higher studies. By utilising these indicators of 'quality', students navigated a range of assumptions that positioned minority language education as low-quality education. Further, this performance of quality strengthened the reputation of the schools as 'good schools' and served to address any lingering doubts about mother-tongue education. The idea that mother-tongue education was geared towards uniform national education goals provided an acceptable framework in the general context of underachievement in education and deep-rooted tensions around issues of ethnicity in Nepal.

In the empirical context of Nepal, the article cautions against the trend of associating the social prestige of language as 'quality' in education. The cases discussed in this article reiterate that 'quality education' may not always be as neutral a category as assumed in mainstream education programmes. By foregrounding the issue of power relations embedded in the perception of 'quality' in minority-language education, this article intends to be of wider analytical relevance to socially heterogeneous contexts beyond Nepal.

\section{Notes}

1. I have used the terms mother tongue and minority languages synonymously throughout this article.

2. Nepal Bhasa is the language spoken by Newars, one of the ethnic groups in Nepal. Although 'Nepal Bhasa' literally means Nepalese language, it is different from the 'Nepali' language, the official language of Nepal. Nepal Bhasa is also commonly known as Newari. However, many ethnic Newar organisations have strongly opposed the use of the term 'Newari' as it was considered to be imposed externally and did not reflect its long-standing history (see Gellner 1986). The census of Nepal now uses 'Nepal Bhasa' to denote the language spoken by Newars. In this article, I have used Nepal Bhasa, to reflect the term chosen self consciously by Newar ethnic activists and used by the Nepali state as a census category.

3. There are at least nine different Tharu languages spoken across Nepal (Guneratne 1998). The Tharu spoken at Budhhabhumi, Kapilbastu is called Dangaura Tharu. 
4. UN Sustainable Goals at https://www.un.org/sustainabledevelopment/education/ (accessed on January 1, 2018).

5. In 2009, the Government of Nepal launched a pilotMulti-Lingual Education (MLE) project in seven primary schools (UNESCO 2011). This was followed by the School Sector Reform Plan (SSRP), in which the government proposed to make multi-lingual education mainstream in 7500 schools by 2015 . Moreover, several ethnic organisations have been teaching ethnic languages to the younger generation in their mothertongue schools across Nepal.

6. Informal interviews with Janak Shrestha were conducted on Newa School premises (Kathmandu) over a total of 10 sessions between November and December 2013. A formal interview with Janak Shrestha was conducted on 13 November 2013.

7. The word 'boarding' in the name of the school is used colloquially to signal that the school teaches in English. Whether the school has a provision of hostel accommodation is of not much consequence in this nomenclature.

8. Such advertising boards are commonly used by schools that want to attract pupils. It is, therefore, a common practice in fee-paying private schools to place them in the street, not just inside the school.

\section{Acknowledgements}

The author is deeply indebted to the teachers, parents and students of Newa School and Buddhabhumi School for allowing her to be part of their lives during her PhD fieldwork. She is also grateful to the United Mission to Nepal (UMN), Nepa Bhasa Manka Khalah and Newa Thay, Newa Bhay Abhiyan. This research would not have been possible without all the logistical support and countless insightful discussions with the members of these organisations. This paper has enormously benefitted from the feedback from Nandini Gooptu, David Gellner and David Mills at the University of Oxford and Mark Turin at the British University of Colombia. Fieldwork for this research was made possible through ODID and a Wolfson College fieldwork grant. All errors remain the author's own. 